\title{
CORRECTION
}

\section{Correction to: Injection Technique Education in Patients with Diabetes Injecting Insulin into Areas of Lipohypertrophy: A Randomized Controlled Trial}

Liming Chen $\cdot$ Qiuling Xing $\cdot$ Jing Li $\cdot$ Jianxin Zhou $\cdot$

Yi Yuan · Ying Wan · Brian K. Pflug · Kenneth W. Strauss ·

Laurence J. Hirsch

Published online: May 18, 2021

(c) The Author(s) 2021

Correction to: Diabetes Ther (2021) 12:813-826

https://doi.org/10.1007/s13300-021-01013-1

In the original article, there is an error in the results section of the abstract. The correct sentence should read as "Changes in TDD insulin in

The original article can be found online at https://doi. org/10.1007/s13300-021-01013-1.

L. Chen $(\varangle) \cdot$ Q. Xing $\cdot$ J. Li $\cdot$ J. Zhou

NHC Key Laboratory of Hormone and

Development, Tianjin Key Laboratory of Metabolic

Diseases, Chu Hsien-I Memorial Hospital and

Tianjin Institute of Endocrinology, Tianjin Medical

University, Tianjin, China

e-mail: xfx22081@vip.163.com

\section{Y. Yuan}

Medical Affairs, Becton Dickinson and Company, Inc., Shanghai, China

Y. Wan · B. K. Pflug

Diabetes Care, Becton Dickinson and Company, Inc., Franklin Lakes, NJ, USA

K. W. Strauss

Former Global Medical Affairs, BD Diabetes Care, Becton Dickinson and Company, Inc.,

Erembodegem, Belgium

\section{J. Hirsch}

Former Global Medical Affairs, BD Diabetes Care, Becton Dickinson and Company, Inc., Franklin

Lakes, NJ 07417, USA the IT-education group were approximately -7 and $-8 \mathrm{IU}$ by the ITT and PP analyses, respectively, versus - 1 IU (nonsignificant) in the controls (both between-group differences $p<0.05$ )".

In the original article, there is an error in Fig. 1. The correct Fig. 1 is given below. 

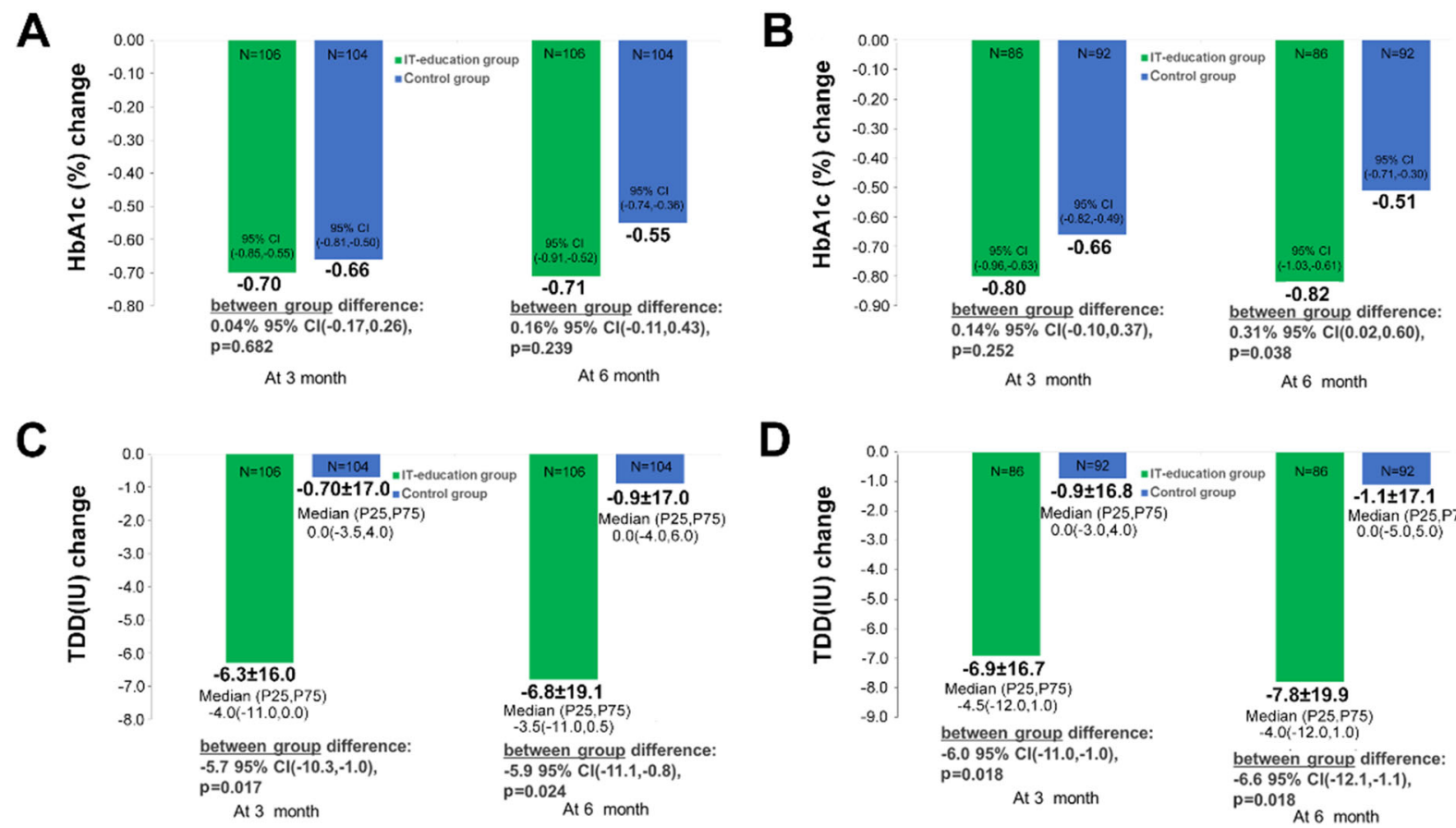

D

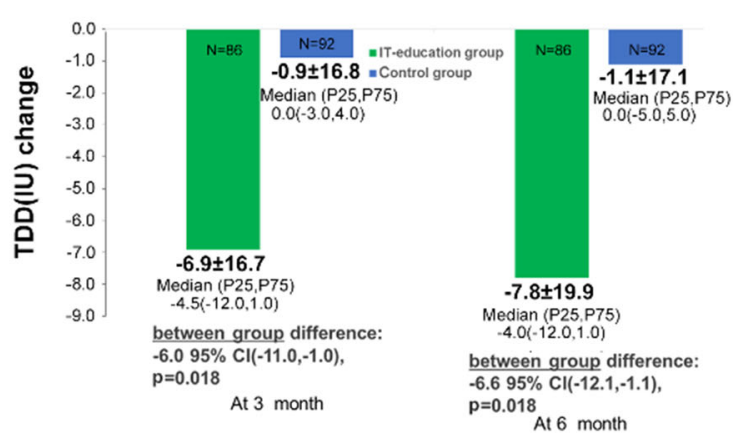

Fig. 1 Changes in study endpoints from baseline to 3 and 6 months. a Change in glycated hemoglobin ( $H b A 1 c)$ from baseline to 3 and 6 months, overall (ITT). b HbAlc change from baseline to 3 and 6 months, overall (PP).

Open Access. This article is licensed under a Creative Commons Attribution-NonCommercial 4.0 International License, which permits any non-commercial use, sharing, adaptation, distribution and reproduction in any medium or format, as long as you give appropriate credit to the original author(s) and the source, provide a link to the Creative Commons licence, and indicate if changes were made. The images or other third party material in this article are included in the article's Creative Commons

c Change in total daily dose (TDD) from baseline to 3 and 6 months (ITT). d Change in TDD from baseline to 3 and 6 months (PP). CI Confidence interval, ITT intention to treat, $P P$ per protocol

licence, unless indicated otherwise in a credit line to the material. If material is not included in the article's Creative Commons licence and your intended use is not permitted by statutory regulation or exceeds the permitted use, you will need to obtain permission directly from the copyright holder. To view a copy of this licence, visit http://creativecommons.org/licenses/by$\mathrm{nc} / 4.0 /$. 